\title{
A Comparative Study of the Interaction Features of Barrage and Forum in Social Learning Course
}

\author{
Xin An, Xue Gong, Rongchi Zhao, Qiuyu Chen, and Ning Ma
}

\begin{abstract}
Forum as an effective way for learners and instructors to communicate has been widely used in online learning, but there are still some unsolved problems in online learning, such as loneliness and lack of motivation. With the development of the technology of barrage, some teaching videos try to add the barrage function. As a virtual synchronous interaction way based on situation, interaction on barrage is different from the traditional online discussion and question-answering areas. In this paper, the content analysis method is used to analyze a Japanese teaching course on Bilibili website. It is found that there were differences in the number, length, interactive objects and interactive content between barrage and forum. This conclusion provides some valuable ideas for solving the problems of loneliness and lack of motivation in distance learning.
\end{abstract}

Index Terms - Interaction, feature, barrage, forum, online learning, Bilibili.

\section{INTRODUCTION}

With the wide application of computer networks and the development of information technology, human society entered the information age in the 21 st century, in which the way of learning and teaching has also changed. The continuous application of information technology in the field of education has led to the rapid development of interest in online education within the last decade [1], [2]. For example, the number of education institutions offering and the number of learners registered for online courses have increased exponentially [3]. Moreover, since 2012, the development of MOOCs has pushed the development of online learning platforms to the peak of the online education wave [4]. However, although the value of online learning is widely recognized and the interest in it has rapidly increased around the world, the dropout rates in and the number of dissatisfied learners with online courses have also increased [5]. Based on previous research, one of the major factors is the issue of interaction in the online learning process, which is viewed as the biggest concerns with online education [6].

In online learning context, the interaction between learners and learners, teachers and learners in and out of class is very important. According to social constructivist theory, learning is more effective when learners are able to discuss with others their perceptions and experiences [7]. Simply, as Kurucay and Inan's research [3] reported, online leaners studying with effective interaction achieved significantly higher than those

Manuscript received May 20, 2019; revised March 12, 2020.

The authors are with Beijing Normal University, Beijing, China (correspond author: Ning Ma; e-mail: 1050138645@qq.com, 1143233756@qq.com, 15850586823@163.com, horsening@bnu.edu.cn). working individually. Therefore, many educators have claimed that enhancing interactivity in online learning context by creating an interactive learning environment is crucial to the learning and success of the learners [8]. For instance, the online forum area can make the interaction in online courses more convenient. More specifically, the online forums could provide a channel for learners to ask questions from teachers and learners, to express opinions, and get feedback [9]. Previous studies have found that the use of the online discussion areas has a positive impact on school performance [10]. However, researchers have not reached a consensus on the effectiveness of the forum comment area in online learning environments [11]. As the discussion forum is asynchronous, it allows more flexibility in schedule for learners, which also means that collaboration and interactive learning would not necessarily happened in all participants [12], [13]. Indeed, Hewitt [14] reported that online forum participation is often found to be fragmented and scattered, which would lead to the loneliness and the sense of low social presence [6]. Social presence is the degree to which a person is considered to be a "real person" and the degree of connection with others in the process of communicating with the media [15].

With the rise of the barrage video, the way the barrage interacts has attracted the attention of scholars. The term "barrage" was first used in military terms. The emergence of a barrage shooting game in Japan first brought the word to the ACGN (Animation Comic Game and Novel) community. The barrage video originated from a video website named "niconico" in Japan. The viewers who watched the video were able to send and present timely information according to the personal emotions and opinions when watching the video, and realized interaction with other video viewers. After the barrage comments is posted, the comment content will be displayed on the video screen in the form of horizontal scrolling or closed captions for a few seconds. Barrage comments can give viewers the illusion of "real-time interaction". Although different barrage comments are sent at different times, they only appear at a specific point in the video. Therefore, the barrage comments sent at the same time basically have the same theme, and there will be an illusion of simultaneous comments with other viewers when participating in the comment. The traditional forum comment area is independent of the player, so the content of the comments mostly revolves around the entire video, and there is no unified topic point and "real-time interaction" feeling. Some scholars believe that barrage interaction may make up for some of the shortcomings of traditional online learning forums. Barrage can increase the fun of video and help viewers understand video content [16]. Some scholars have 
suggested that the bullet-screen commentary area in MOOC may bring new development opportunities to online learning. The strong interactivity of the barrage commentary will likely solve the problem of "learner's lack of continuous learning and lack of communication and interaction" [17].

Both the forum comment area and the barrage comment area have their own features. Although the emergence of barrage and its advantages seem to fill the flaws of the forum, barrage has less research on academic learning. This study compares the interaction features of the teaching video's barrage comment area with the forum comment area, and aims to provide some reference for solving the interactive problem of distance education. Therefore, this paper proposes the following two research questions :

1) What are the interaction features of the online learning forum and the barrage?

2) What role can the two interactions play in online learning?

\section{METHOD}

\section{A. Research Context}

This study investigates the interactive texts of learners in a Japanese Fifty-tone teaching course on Bilibili (https://www.bilibili.com/), a barrage video website. When the video is created, it will be uploaded to the Bilibili website, just like the YouTube website. Each uploaded video has a barrage comment area and a forum comment area. People can post comments anonymously in the barrage comment area, but comments in the forum comment area show the publisher's nickname. Unlike other online learning website, there is no teacher's guidance and feedback, so all the interactions are spontaneously carried out by learners. This course is an introductory course of Japanese language learning

(https://www.bilibili.com/video/av1111459?from=search\&s eid=12387750813496728544), mainly about Japanese pronunciation and simple Japanese words, which has more than 35 thousand barrage comments and more than 7,000 comments in the forum as for December 2018. Therefore, the learners need to repeat practicing to deepen the memory.

\section{B. Instrument}

In order to present the rules and characteristics of interactions in the form of data, content analysis method was used in this study to quantifies the interaction process by coding the message records of synchronous online interaction learning. All comments were coded by four independent coders who received training in the coding schemes. As no previous studies have been conducted on the classification of barrage comments, this study refers to Social Presence Assessing Model [18], Know Construction Category System [7] and Interaction Analysis Model for SPOC Forum [19]. Combining the characteristics of barrage, we compile a new analysis model for barrage and forum comments. The final analysis model is formed by four researchers' trial encode and several modifications, which named Interaction Analysis Model for Barrage and Forum (IAMBF), as shown in Table I.

\begin{tabular}{|c|c|c|}
\hline Code & $\begin{array}{l}\text { Comments } \\
\text { classification }\end{array}$ & Category and description \\
\hline 1 & $\begin{array}{l}\text { Discussing the } \\
\text { Learning } \\
\text { Content }\end{array}$ & $\begin{array}{l}\text { Discussing the learning content, } \\
\text { including question, reply, clarification, } \\
\text { interpretation, conflict, assertion, } \\
\text { consensus building, judgment, reflection, } \\
\text { support, etc. }\end{array}$ \\
\hline 2 & $\begin{array}{l}\text { Repeating the } \\
\text { Learning } \\
\text { Content }\end{array}$ & $\begin{array}{l}\text { Simply repeating the words just taught in } \\
\text { the video. }\end{array}$ \\
\hline 3 & $\begin{array}{l}\text { Rituals of } \\
\text { Online Learning }\end{array}$ & $\begin{array}{l}\text { Some special behaviors with regular } \\
\text { patterns or procedures at some specific } \\
\text { situations acted by the community with a } \\
\text { common culture (Leach,1966; } \\
\text { Turner,1969) who learn online }\end{array}$ \\
\hline 4 & $\begin{array}{l}\text { Expression of } \\
\text { Emotion }\end{array}$ & $\begin{array}{l}\text { Expressing one's own emotions to } \\
\text { something when watching the video, } \\
\text { including love, joy, surprise, angry, } \\
\text { sadness and fear (Shaver,1987). }\end{array}$ \\
\hline 5 & $\begin{array}{l}\text { Resource } \\
\text { Sharing }\end{array}$ & Sharing learning resources \\
\hline 6 & Other content & $\begin{array}{l}\text { Some mixed messages difficult to } \\
\text { categorize and social statements, and } \\
\text { other comments that are difficult to } \\
\text { identify semantics }\end{array}$ \\
\hline
\end{tabular}

In order to ensure the consistency of the raters, this study adopts the method of equal proportion sampling to randomly select 40 and 160 comments from forum and barrage respectively for co-coding before the coders officially code. Since there are replying comments in the forum, the final number of comment samples in the forum is 117. According to the Kendall harmony coefficient, the consistency reliability of the graders was calculated, and the Kendall coefficient of forum and barrage was 0.803 and 0.939 respectively, which means that four coders are applying essentially the same standard when code the samples. After the co-coding, four coders also discussed all the discrepancies face-to-face until a consensus coding was achieved.

\section{RESULTS}

\section{A. Research Context}

There are 35,385 barrage comments and 7,027 forum comments in this Japanese teaching course. After encoding and analyzing the content, the basic features of the barrage interaction comments and the forum interaction comments are summarized, as is shown in Table II. The difference in the number of interaction comments between the barrage area and the forum area may be related to the anonymity of the comments. Studies have shown that the use of anonymous user methods in online classrooms is an effective way to promote class discussion, which promotes more and better participation of marginal learners in the classroom [20].

In terms of the length of the statement, the statements of the barrage comment are usually shorter, with an average length of 12.20 English characters, while the comment in the forum area is longer, with an average length of 125.08 English characters It is not convenient to enter long sentences when posting a barrage comment. Even if you enter a long sentence, you cannot display it on the video screen for a long time, so that others may not have finished reading your comment. 
When it comes to the pertinence of interactive objects, most of the interactive objects of the barrage comments are not clear and open-ended, which send to all learners watching video. There are only $2.10 \%$ comments that have clear interactive objects, including "front", "red" characters, "Yellow word", "another little friend", “ $\uparrow "$ and other referential words or symbols. However, the forum area has a big difference on the pertinence of interactive objects. Among them, $28.62 \%$ of the comments have clear interactive objects, which are reflected directly under the original post, or directly “@”, someone.

TABLE II: COMPARISON OF THE INTERACTION FEATURES OF BARRAGE INTERACTION AND FORUM

\begin{tabular}{lll}
\hline \hline Basic Features & Barrage Area & Forum Area \\
\hline Anonymous or not & Yes & No \\
Number of comments & More (35385) & Less (7027) \\
Statement length & Shorter (12.20) & Longer (125.08) \\
Interactive object & Less specific & More specific \\
& $(2.10 \%)$ & $(28.62 \%)$ \\
\hline \hline
\end{tabular}

\section{B. Interactive Content Features of the Two Types of Interactions}

The results of encoding the contents of barrage and forum are shown in Table III. More than half of the comments in the barrage area are Repeating the Learning Content, which is significantly different from the forum area. There are very few comments of Repeating the Learning Content in the forum area, which only accounts for $2.16 \%$. Comparing to comments of Resource Sharing in the barrage area $(0.39 \%)$, there are more comments of Resource Sharing in the forum area, accounting for $20.05 \%$. Most of the comments in the forum area are Rituals of Online Learning (39.86\%). Although the proportion of Rituals of Online Learning in the forum area is larger, the actual number is not as large as the barrage area.

TABLE III: INTERACTION ANALYSIS RESULT OF BARRAGE AND FORUM

\begin{tabular}{|c|c|c|c|}
\hline code & $\begin{array}{l}\text { Comments } \\
\text { classification }\end{array}$ & barrage & forum \\
\hline 1 & $\begin{array}{l}\text { Discussing the } \\
\text { Learning Content }\end{array}$ & $1696(4.79 \%)$ & $606(8.62 \%)$ \\
\hline 2 & $\begin{array}{l}\text { Repeating the Learning } \\
\text { Content }\end{array}$ & $19027(53.77 \%)$ & $152(2.16 \%)$ \\
\hline 3 & $\begin{array}{l}\text { Rituals of Online } \\
\text { Learning }\end{array}$ & $6268(17.71 \%)$ & $2801(39.86 \%)$ \\
\hline 4 & $\begin{array}{l}\text { Expressions of } \\
\text { emotion }\end{array}$ & $3608(10.20 \%)$ & $1052(14.97 \%)$ \\
\hline 5 & Resource Sharing & $138(0.39 \%)$ & $1409(20.05 \%)$ \\
\hline 6 & Other content & $4136(11.69 \%)$ & $1007(14.33 \%)$ \\
\hline
\end{tabular}

1) Comments about learning content

There are significant differences between barrage and forum in communication of learning content, which may lead them to be two different ways of assisting online learning. This difference may be due to the different basic characteristics of the barrage and the forum.

Learners prefer to send barrages to do intensive practices of learning content immediately while watching the video, as a result that there are more than half the number of the barrages $(19,027)$ to repeat the learning content following teacher. Deeply watch and analysis the video, we found there were usually plenty of barrages repeating the words or pronunciation when the teacher in video were teaching something new, even blocking the whole screen. By contrast, there are only $2.16 \%$ interactions in forum Repeating the Learning Content, which indicates the forum is not usually used for practicing learning content.

In the forum, learners are more willing to discuss some questions about learning content in depth, such as questions, answers, and refutations, which take a percentage of $8.62 \%$, rather than simply mechanical repetition of learning content. Therefore, in the forum, learners' level of interactive knowledge construction should be significantly higher than that of barrage. Therefore, it is easy to deduce the conclusion that forum is more suitable for in-depth learning than barrage. 2) The Rituals of Online Learning

Rituals of Online Learning is defined as some special behaviors with regular patterns or procedures at some specific situations acted by a community with a common culture (Leach, 1966; Turner, 1969) who learn online. In this study, the researchers found that rituals in this course include sending a message of the learning date when get ready for learning, sharing the learning progress at some special moments, indicating their group identity and simulating the behaviors in real class at some special situations.

Since the research content we selected is a language teaching video, there are many comments of Repeating the Learning Content in the barrage comments, accounting for $53.77 \%$, which leads to a small proportion of other types of comments in the barrage commentary. Therefore, we will analyze the content of the interactions of barrage and forum to find their differences.

Learners like sending some messages to symbolize that they join in the class in Bilibili website. In barrage, they preferred to send the data they watched the video, such as "2018.01.02" or "180607", which has become a distinctive landscape in barrage. While in forum, learners preferred to send a comment "sign in" to symbolize they had started to learn, which may because the data in which the comment was sent can be seen in the forum.

Learners not only like symbolize their attendance, but prefer to symbolize the reginal group they belong to through sending barrage, such as "we people born in Sichuan province feel no pressure" or "southern people feel it difficult to pronounce the word", totally 727 sentences. While they say few about their identities in forum, totally 33 sentences, mainly about the age group they belong, such as "98er" (people who born in 1998) or "senior 3 party" (learner who are in senior 3).

In addition, learners prefer to imitate the conversations in real class to create a real classroom atmosphere through sending barrages. For example, the word "classmate" appeared 66 times, and the sentences in which it appeared are usually pretending to talk with a virtual classmate, such as "Lend me a pen, my classmate" or "Let's go to the canteen after class, my classmate". As we all know, there are no classmates, pen or canteen in online learning environment. However, this virtual interaction phenomenon did not appear in the forum.

What's more, learners prefer to share the process of learning by watching the video, such as "Stop to take notes", "Go on after practicing 5 minutes", "I can't remember it" and so on. While they prefer to share the feeling after watching 
the video in forum, such as "I just watched two videos, and now I remember only four of the five basic vowels... The order is also uncertain... Looks like I'm really a learning scum..."

Therefore, we can feel that learners attach great importance to the rituals in both the two ways of online learning communication despite the differences in their expressions, and a unique and tacit culture has been developed in this course, which is hardly seen on formal online learning website.

3) Expression of Emotion of barrage and forum

In terms of Expression of Emotion, there are 3210 emotional interactions in the barrage area and 817 emotional interactions in the forum area. Through the analysis of the content of emotional expression, it is found that emotional expression can be divided into two types: untargeted Expression of Emotion and targeted Expression of Emotion, so the second round of coding was carried out.

Untargeted Expression of Emotion means expressing one's own emotions simply and directly without a specific object in the sentences. Some them are consisting of punctuation marks or simple modal particles, such as "?????" and "!!!", both of which mean the emotion of surprise, and "Hahaha", "hhhhhh", "2333”, all of which mean emotion of joy. Others are "facial characters", which means arranging the order of the combination of the computer characters and forming a pattern that depicts the emotion and action of human, such as" ${ }^{\wedge} \wedge ",,(=\cdot \omega \cdot=)$, and " $\left(\mathrm{T}_{-} \mathrm{T}\right)$ ".

In barrage area, 853 comments are untargeted expressions of emotion, taking a percentage of $23.64 \%$ in all the expressions of emotion of barrage, in which 770(90.27\%) comments are punctuation marks or simple modal particles, and $83(9.73 \%)$ comments are facial characters. While in forum area, 110 comments are targeted Expression of Emotion, taking a percentage of $10.46 \%$ in all the expressions of emotion of forum, in which 13(11.82\%) comments are punctuation marks or simple modal particles, and $97(88.18 \%)$ comments are facial characters, notably.

Targeted Expression of Emotion means emotional expressive comments with clear objects, including teachers, classmates, learning contents and learning medias. For examples, "The teacher is so attractive that I never listened to my teacher so seriously in real class..."(for the teacher), "The forward yellow barrage, you are so excellent!'(for a classmate), "This is too difficult!"(for the learning content) and "The video quality is too bad! I want to watch HD"(for the learning media).

TABLE IV: STATISTICS OF EMOTIONAL EXPRESSIVE COMMENTS

\begin{tabular}{lll}
\hline \hline Type & Barrage & Forum \\
\hline Untargeted Expression & $853(23.64 \%)$ & $110(10.46 \%)$ \\
Targeted Expression & $2755(76.36 \%)$ & $942(89.54 \%)$ \\
\hline \hline
\end{tabular}

In barrage area, 2755 comments are targeted expressions of emotion, taking a percentage of $76.36 \%$ in all the expressions of emotion of barrage. While in forum area, 942 comments are targeted Expression of Emotion, taking a percentage of $89.54 \%$ in all the expressions of emotion of forum. As is shown in Table IV.

4) Learning Resource Sharing

In terms of Resource Sharing, the forum area pays more attention to the request and sharing of learning resources, accounting for $20.50 \%$, while the bullet-screen area only pays less attention to Resource Sharing, only $0.40 \%$.

In the barrage area, the comments of learning Resource Sharing are main about the number of QQ group where learners can communicate or share resources conveniently. While in the forum area, learners prefer to share the link of other related learning videos, which learners can click the link and download the learning videos.

\section{DISCUSSION}

\section{A. The Role of Two Types of Interactions in Knowledge Construction}

The two interactive ways both play an important role in promoting learning effect, and are both essential parts of online learning.

The role of barrage is to provide opportunities for immediate practice and reinforcement in the learning process with the accompany of many learning partners. As we can see in the results, learners like sending barrages to repeat the words or phrases just appearing in the video, which has become a convention in the course. It helps to achieve the learning goal — "knowledge" according to Bloom's Target Classification in Cognitive Domain, which is significate for online learning.

The role of forum is to provide opportunities to communicate more deeply to achieve high-level cognitive goals. As is known in the results, the interactive object in forum is much more specific, and the length of the comments in forum is much longer than they are in barrage. These features make it possible to discuss the learning content further in forum, even to share other learning resources to make up for knowledge deficiencies, which is hard to accomplish in the barrage due to the limitation of anonymity and short length.

\section{B. Social Presence of Online Learning}

Higher level of social presence was perceived by learners in barrage than it in forum. Gunawardena [21] believes that immediacy enhances social presence, which is considered as a significate feature of barrage. In the process of watching the learning video, learners see the barrages based on the current situation of the video sent by other learners, which create a virtual sense of synchronous interaction [22], which means higher level of immediacy. As we can see in the result, the Expression of Emotion in barrage area is more simply and directly, in which the comments of Untargeted Expression of Emotion are more than that is forum.

It is important for online learning to promote the perceptions of social presence. Previous researchers have proved that perceptions of social presence have been positively correlated with course satisfaction [23], and high levels of perceived social presence by learners at the beginning of an online course are linked to high levels of motivation and participation [24]. Therefore, it can be 
considered to add barrage to some formal online learning platforms, such as MOOCs.

\section{The Rituals of Online Learning in Informal Learning Website}

Previous researches show that rituals are important for learning. On the on hand, rituals are symbols of cultural order [25]. As a common value recognized by specific groups, rituals have the function of cohesion and strengthening the sense of group identity [26]. On the other hand, social interactive rituals in specific situations, such as greetings and timely compliments, are conducive to stimulating learning motivation of learners [18].

Therefore, rituals are significant for online learning, where loneliness and loss of motivation are serious problems. As we can see in the results, some rituals have been formed between online learners on the Bilibili website, which is an interesting phenomenon not often seen in formal learning websites, such as MOOCs. We can see the strong learning motivation clearly through barrages and forum on Bilibili website, as so many learners send comments to indicate that they have never learned so seriously in real class as they learn on Bilibili website, such as "I learned so seriously! If my teacher in school see me learning online so seriously, he will surely kill me." We have reason to believe that, the sense of ritual is an indispensable part of learning motivation on Bilibili website. As for learning motivation, follow-up studies can also be carried out in depth.

\section{CONCLUSION}

This study found that there were differences in the number, length, interactive objects and interactive content between barrage and forum, which provides some valuable ideas for solving the problems of loneliness and lack of motivation in distance learning. Further research will be carried out in the follow-up.

\section{CONFLICT OF INTEREST}

The authors declare no conflict of interest.

\section{AUTHOR CONTRIBUTIONS}

Xin An conducted the research; Xin An, Xue Gong, Rongchi Zhao and Qiuyu Chen analyzed the data; Xin An, Xue Gong and Ning Ma wrote the paper. All authors had approved the final version.

\section{REFERENCES}

[1] F. A. Inan, E. Yukselturk, and M. M. Grant, "Profiling potential dropout students by individual characteristics in an online certificate program," International Journal of Instructional Media, vol. 36, no. 2, pp. 163-176, 2009.

[2] J. Larreamendy-Joerns and G. Leinhardt, "Going the distance with online education," Review of Educational Research, vol. 76, no. 4, pp. $567-605,2006$

[3] M. Kurucay and F. A. Inan, "Examining the effects of learner-learner interactions on satisfaction and learning in an online undergraduate course," Computers \& Education, vol. 115, pp. 20-37, 2017.

[4] Y. Wang, J. L. Zhang, and B. H. Zhang, "Analysis and enlightenment of typical project characteristics of large-scale open online course (MOOC)," Journal of Distance Education, vol. 31, no. 4, pp. 67-75, 2013.
[5] G. Rogers, D. S. Finley, and M. Patterson, "Transformation in higher education: a learner-needs segmentation leads to improved learner satisfaction," Teaching in Higher Education, vol. 11, no. 4, pp. 401-411, 2006.

[6] D. Gosmire, M. Morrison, and J. V. Osdel, "Perceptions of interactions in online courses," Journal of Online Learning \& Teaching, vol. 5, no. 4, pp. 609-617, 2009.

[7] J. B. Pena-Shaff and C. Nicholls, "Erratum to: Analyzing student interactions and meaning construction in computer bulletin board discussions," Computers \& Education, vol. 43, no. 3, pp. 313, 2004.

[8] G. Salmon, "E-Moderating: The key to teaching and learning online," Journal of Distance Education, vol. 1, no. 2, pp. 95-104, 2000.

[9] J. Patel and A. Aghayere, "Students' perspective on the impact of a web-based discussion forum on student learning," presented at Frontiers in Education Conference, IEEE, San Diego, CA, USA, Oct. 2006.

[10] N. Gillani and R. Eynon, "Communication patterns in massively open online courses," Internet \& Higher Education, vol. 23, no. 5, pp. 18-26, 2014.

[11] J. Robinson, "Assessing the value of using an online discussion board for engaging students," The Journal of Hospitality Leisure Sport and Tourism, vol. 10, no. 1, pp. 13-22, 2011.

[12] K. Kreijns, P. A. Kirschner, and W. Jochems, "Identifying the pitfalls for social interaction in computer-supported collaborative learning environments: A review of the research," Computers in Human Behavior, vol. 19, no. 3, pp. 335-353, 2003.

[13] S. Vonderwell, "An examination of asynchronous communication experiences and perspectives of students in an online course: A case study," Internet \& Higher Education, vol. 6, no. 1, pp. 77-90, 2003.

[14] J. Hewitt, "Toward an understanding of how threads die in asynchronous computer conferences," Journal of the Learning Sciences, vol. 14, no. 4, pp. 567-589, 2005.

[15] J. Short, E. Williams, and B. Christie, "The social psychology of telecommunication," Telecommunications Policy, vol. 1, no. 2, pp. 175-176, 1977.

[16] C. Zhang, "Interactive status and development strategy of barrage video," Young Journalists, no. 5, pp. 65-66, 2015.

[17] H. F. Li and W. Wang, "Barrage video: A new orientation of online video interactive learning," Modern Educational Technology, vol. 25, no. 06, pp. 12-17, 2015.

[18] L. Rourke, T. Anderson, D. R. Garrison, and W. Archer, "Assessing social presence in asynchronous text-based computer conferencing," Journal of Distance Education, vol. 14, pp. 50-71, 1999.

[19] W. J. Zhang, "Interactive behavior and emotional analysis of learners' discourse in SPOC forum," 2018, Central China Normal University.

[20] Y. M. Liang, "Research on the practice of anonymous users in online classroom," 2010, Shanghai Normal University.

[21] C. N. Gunawardena, "Social presence theory and implications for interaction collaborative learning in computer conferences," vol. 1, no. 2/3, pp. 147-166, 1995.

[22] J. J. Zhang, Y. H. Yang, and X. An, "Learning interaction analysis in barrage video," Distance Education in China, no. 11, pp. 22-30, 2017.

[23] C. N. Gunawardena and F. J. Zittle, "Social presence as a predictor of satisfaction within a computer ediated conferencing environment," American Journal of Distance Education, vol. 11, no. 3, pp. 8-26, 1997.

[24] C. Savvidou, “'Thanks for sharing your story': The role of the teacher in facilitating social presence in online discussion," Technology Pedagogy \& Education, vol. 22, no. 2, pp. 193-211, 2013.

[25] Z. F. Luo, "Genealogy and interpretation of rituals: Reading the theory and practice of anthropological rituals," World Ethnic Groups, no. 3, pp. 94-96, 2011.

[26] Y. F. Fang, "Ritual sense marketing," Sales and Marketing (Management Edition), no. 6, pp. 67-69, 2011.

Copyright $\odot 2020$ by the authors. This is an open access article distributed under the Creative Commons Attribution License which permits unrestricted use, distribution, and reproduction in any medium, provided the original work is properly cited (CC BY 4.0).

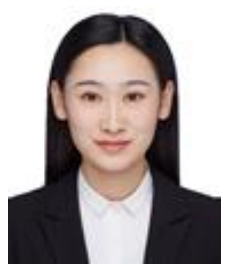

Xin An was born in Shandong, China in 1995. She got a bachelor's degree in educational technology from Beijing Normal University in 2018, and now she is a master student whose major is educational technology in Beijing Normal University. Her major research field is the assessment of online learning.

She worked as a computer teacher in Yuyuantan Middle School in 2017. And she has worked on White 
Paper on Internet Learning in China under the guidance of her tutor since 2017. Now she is studying the measurement of online learning as a master student.

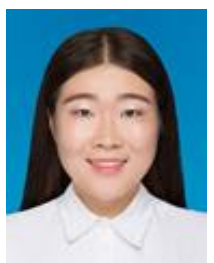

Xue Gong was born in Linyi City, Shandong province, China, on May 18, 1996. In 2018, she obtained a bachelor of science degree in education technology from Shandong Normal University. She is currently pursuing a master's degree in physiology in the field of educational technology at Beijing Normal University.

She has won several first-class scholarships in Shandong Normal University. She devoted to poverty-stricken areas in Heze City of Shandong Province to aid education in the summer of 2016. Her teaching group won the title of "Excellent Service Team for Shandong University Student Education Activities". In 2017, he won the National Inspirational Scholarship and the third prize of the Chinese University Student Computer Design Competition. In 2018, She was named outstanding graduate of Shandong Province. Now she is engaged in research study at the School of Education and Technology of the Beijing Normal University. The research direction is Internet learning assessment.



Rongchi Zhao was born in Changde, Hunan province, China in 1995. She got her bachelor's degree in educational technology from Beijing Normal University in 2018, and now she is a master student whose major is Educational Technology in Beijing Normal University. Her major research field is the teaching of thinking.

She worked as a math teacher in Beijing Normal University Chaoyang Primary School in 2017. And she has worked on Teaching of Thinking program under the guidance of her tutor since 2016. Now she is studying the teaching of thinking as a master student.

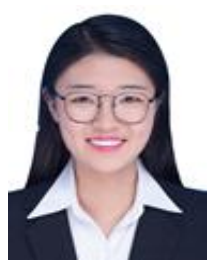

Qiuyu Chen was born on October 1995 in Nantong, Jiangsu province. She received her bachelor's degree in educational technology from Nanjing University of Posts and Telecommunications in 2018. Her major research field is information technology curriculum integration.

Now she is studying information technology curriculum iteration as a master student in Beijing

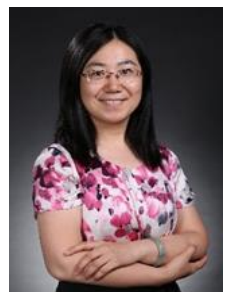

Ning Ma was born in Hebei, China in 1977. She received her doctor's degree in education from Beijing Normal University, Beijing, China in 2006. Her major study focused on technology enhanced K-12 learning and technology enhanced teacher development.

She began her work as a lecturer in School of Educational Technology, Beijing Normal University in 2006. Then, she became a master's supervisor in 2009 and an associate professor from 2014. From September 2015 to August 2016, she has been an academic visitor (Honorary Senior Research Associate) in the Department of Culture, Communication and Media (CCM), UCL Institute of Education. Now, she is an associate professor in the Faculty of Education, Beijing Normal University. She has been working in the technology enhanced K-12 learning over 13 years. She participated and conducted many research projects, some of which are very influential in China, such as the Project of Theoretical and Practical Innovative Experimental Research on Leaping Development of Fundamental Education which has more than 400 experimental schools in China, Theoretical and Practical Research on Propelling the High Quality and Balanced Development of Regional Compulsory Education which cares about how the K-12 schools in rural areas can get high quality educations, Cloud Classrooms of Mobile Learning supported by the Joint Laboratory of the Ministry of Education and China Mobile Ltd which aims to develop 100 K-12 schools where in some classes each student can learning with a tablet computer or other mobile devices. Her current researches focus on one to one digital learning, mobile learning, and technology enhanced K-12 teacher development. Till now, she has published more than 50 articles and nearly 10 books in these research areas.

Prof. Ma serves as the head of Training Department of the Knowledge Media Lab at Beijing Normal University, deputy director of the Mobile Learning- the Joint Laboratory of the Ministry of Education and China Mobile Ltd, core fellow of the Advanced Innovation Center for Future Education, Beijing Normal University. She was a fellow of the Project of Promoting the K-12 Teachers' Abilities of Applying ICT in Education which sponsored and conducted by the Chinese Ministry of Education aims to training the whole over 100 million K-12 teachers of China.

Normal University. 